\title{
Rib fractures after blunt thoracic trauma in patients with normal versus diminished bone mineral density: a retrospective cohort study
}

\author{
J. T. H. Prins ${ }^{1}$ • E. M. M. Van Lieshout ${ }^{1}$ (D) • M. R. L. Reijnders ${ }^{1}$ • M. H. J. Verhofstad ${ }^{1}$ - M. M. E. Wijffels ${ }^{1}$
}

Received: 15 July 2019 / Accepted: 30 October 2019/Published online: 11 December 2019

(C) The Author(s) 2019

\begin{abstract}
This study aimed to evaluate rib fracture rate as well as rib fracture characteristics after thoracic trauma in patients with normal versus diminished bone mineral density (BMD). A retrospective cohort study of persons aged 50 years or older presenting to the Emergency Department after sustaining blunt thoracic trauma between July 1, 2014, and December 31, 2017, was performed. Patient and trauma characteristics and DXA scan results were collected. Rib fracture rate and characteristics were evaluated on a radiograph and/or CT scan of the thorax. In total, 119 patients were included for analysis. Fifty-eight of them (49\%) had a diminished BMD. In the remaining 61, the BMD was normal. The diminished BMD group experienced rib fractures more often than the normal BMD group ( $n=43(74 \%)$ versus $n=31(51 \%) ; p=0.014)$. Patients with diminished BMD suffered low-energy trauma more frequently than the normal BMD group (21 (36\%) versus 11 patients $(15 \%)$, respectively $(p=0.011)$ ). Rib fracture characteristics such as the median number of rib fractures, concomitant intrathoracic injury rate, and rib fracture type distribution were not different between the groups. The rate of rib fractures after blunt thoracic trauma was significantly higher in patients with diminished BMD than in patients with a normal BMD. Differences in number and location of rib fractures between groups could not be proven. When assessing patients aged 50 years or older presenting to the hospital after substantial blunt thoracic trauma, the presence of diminished BMD should be taken into account and the presence of rib fractures should be investigated with appropriate diagnostic procedures. Diminished bone mineral density (i.e., osteopenia or osteoporosis) is associated with increased fracture risk. This study evaluated if diminished BMD increases the rib fracture risk. Patients with diminished BMD have a higher risk of sustaining rib fractures after substantial blunt thoracic trauma, which implicates a lower threshold for CT imaging of the chest.
\end{abstract}

Keywords BMD $\cdot$ Bone mineral density $\cdot$ Osteopenia $\cdot$ Osteoporosis $\cdot$ Rib fracture $\cdot$ Thoracic trauma

\section{Introduction}

Rib fractures account for approximately $10 \%$ of all trauma admissions and are seen in up to $39 \%$ of patients sustaining blunt thoracic trauma [1-4]. Young patients often suffer rib fractures after high-energy trauma (HET) such as a motor vehicle collision (MVC) or a fall from height [5]. In elderly patients aged 65 years or older, over $50 \%$ have sustained rib fractures following low-energy trauma (LET) such as a fall from standing height $[6,7]$. The number of rib fractures, pre-

E. M. M. Van Lieshout

e.vanlieshout@erasmusmc.nl

1 Trauma Research Unit, Department of Surgery, Erasmus MC, University Medical Center Rotterdam, P.O. Box 2040, 3000 CA Rotterdam, The Netherlands existent pulmonary pathology, and age are known risk factors for rib fracture-associated mortality and morbidity [2-4, $7-13]$. Rib fractures are the most common fractures in men and second most common in women over 65 years [14-16]. The mortality of rib fracture patients over 65 years is two- to fivefold higher than younger patients with similar injuries; therefore, this is a vulnerable patient group [7, 11].

Besides age, diminished bone mineral density (BMD) has been shown to increase fracture risk [17-20]. Osteoporosis, defined by the World Health Organization (WHO) as a BMD T-score of -2.5 and lower, is a common and increasing disease resulting in a higher risk of spine, hip, and wrist fractures [21, 22]. In Europe, 27.5 million people suffer from osteoporosis and 3.5 million new fragility fractures are sustained annually [23].

Diminished BMD also increases the risk of rib fractures after blunt thoracic trauma $[15,24,25]$. In addition, a history 
of one or more rib fractures doubles the risk of any subsequent fracture, suggesting this to be a consequence of a diminished BMD [14, 15, 26, 27]. Concomitant injury after rib fractures is common $[4,6,12,28]$. Thus, an increased probability of serious injury might be considered in patients aged 50 or older, even when rib fractures are sustained after low-energy trauma. The primary aim of this study was to determine the rate of rib fractures in patients with normal versus diminished BMD (i.e., osteopenia or osteoporosis) after blunt thoracic trauma. Secondary aims were to determine the number of fractures, the occurrence of concomitant intrathoracic injuries, and the rib fracture types in these patients.

\section{Methods}

\section{Design and participants}

A retrospective observational cohort study was conducted at a level 1 trauma center after approval by the local Medical Research Ethics Committee. All persons aged 50 years or older who attended the Emergency Department after having sustained blunt thoracic trauma in the period between July 1, 2014, and December 31, 2017, were considered eligible. Blunt thoracic trauma was defined as motor vehicle collisions, falls, vehicle versus pedestrian, acts of violence, and blast injury, excluding all penetrating trauma such as stabbings and gunshots, as registered by the care provider at Emergency Department admission [29]. Patients were identified from the Trauma Department's osteoporosis registry. This registry includes all patients who attended the Emergency Department and were aged 50 years or older with a recently sustained fracture. These patients were invited for osteoporosis screening. The criteria for obtaining a DXA scan are an age of 50 years and older and having sustained a fracture or patients with a significantly increased fracture risk (e.g., the disorders mentioned in exclusion criterion 2, see below).

Patients with any of the following criteria were excluded: (1) time lapse of $>12$ months between thoracic trauma and DXA scan (as the BMD might have changed over this period of time); (2) (congenital) skeletal disorders associated with increased fracture risk (e.g., osteomalacia, Paget's disease, osteogenesis imperfecta, or malignancy [30]); (3) no results of osteoporosis screening registered in the patient's medical files or osteoporosis registry; (4) patients who were listed as having sustained thoracic trauma but no details on thoracic trauma were registered in the medical files; or (5) no radiographic image(s) of rib fractures available in the patient's electronic medical record (either thoracic CT scan or thoracic X-ray).

\section{Data collection and outcome measures}

Data were extracted from the patient's electronic medical record. The presence of at least one rib fracture as seen on X-ray or CT scan of the thorax served as the primary outcome measure. If available, the findings of the CT were used for analysis.

Secondary outcome measures were:

- Characteristics of rib fractures (as reported in the radiology report): number of fractured ribs (i.e., ribs 1 to 12); location of the fractured rib(s) (i.e., cranial (ribs 1-3), middle (ribs 4-10), or caudal (ribs 11-12) segment of the chest wall); location of the fracture (i.e., anterior, costochondral junction to axillary line at one-third of the rib length; axillary, from axillary line to the point perpendicular to a vertical line down from the inferior angle of the scapula; posterior, from axillary endpoint to the joint between transverse process and costal end, or overlapping between the three locations); the affected side (i.e., left, right, or both), presence of a flail chest (defined as three or more consecutive ribs fractured at two or more places [31, 32]), presence of concomitant intrathoracic injuries (i.e., pulmonary contusion, pneumothorax, hemothorax, intrathoracic bleeding, or arterial dissection)

- Classification of every rib fracture seen on the CT scan (type A, non-displaced fracture; type B, > 2-mm displaced fracture; type C, complex fracture) (Fig. 1) [33]. Classifications were done by a trained researcher (MRLR) and checked by a trauma surgeon (MMEW)

In addition to the outcome measures, the following data were collected from the patient's electronic medical record: intrinsic variables (i.e., age, gender, and DXA scan result (lowest T-score of either the proximal femur or lower lumbar spine, and BMD categorization as normal, T-score $>-1.0$; osteopenia, T-score of -1.0 to -2.5 ; or osteoporosis, T-score $<-2.5)$ ) and suspected trauma mechanism defined as HET (traffic accident, pedestrian or person on bicycle hit by vehicle with a speed $>10 \mathrm{~km} / \mathrm{h}$ or any other accident involving vehicles with a speed $>45 \mathrm{~km} / \mathrm{h}$; fall from height, fall from $>2$ times standing height; and other, trauma described as HET in the patient file that was not fall or traffic related) or LET (traffic accident, any traffic accident with speed lower than described for high-energy trauma; fall, fall from maximally standing height; and other, trauma described as LET in the patient file that was not a fall or traffic related, i.e., lowenergy trauma or high-energy trauma).

\section{Statistical analysis}

Data were analyzed using the Statistical Package for the Social Sciences (SPSS) version 24.0 (SPSS, Chicago, IL, USA). 
Fig. 1 Classification of rib fractures
Type

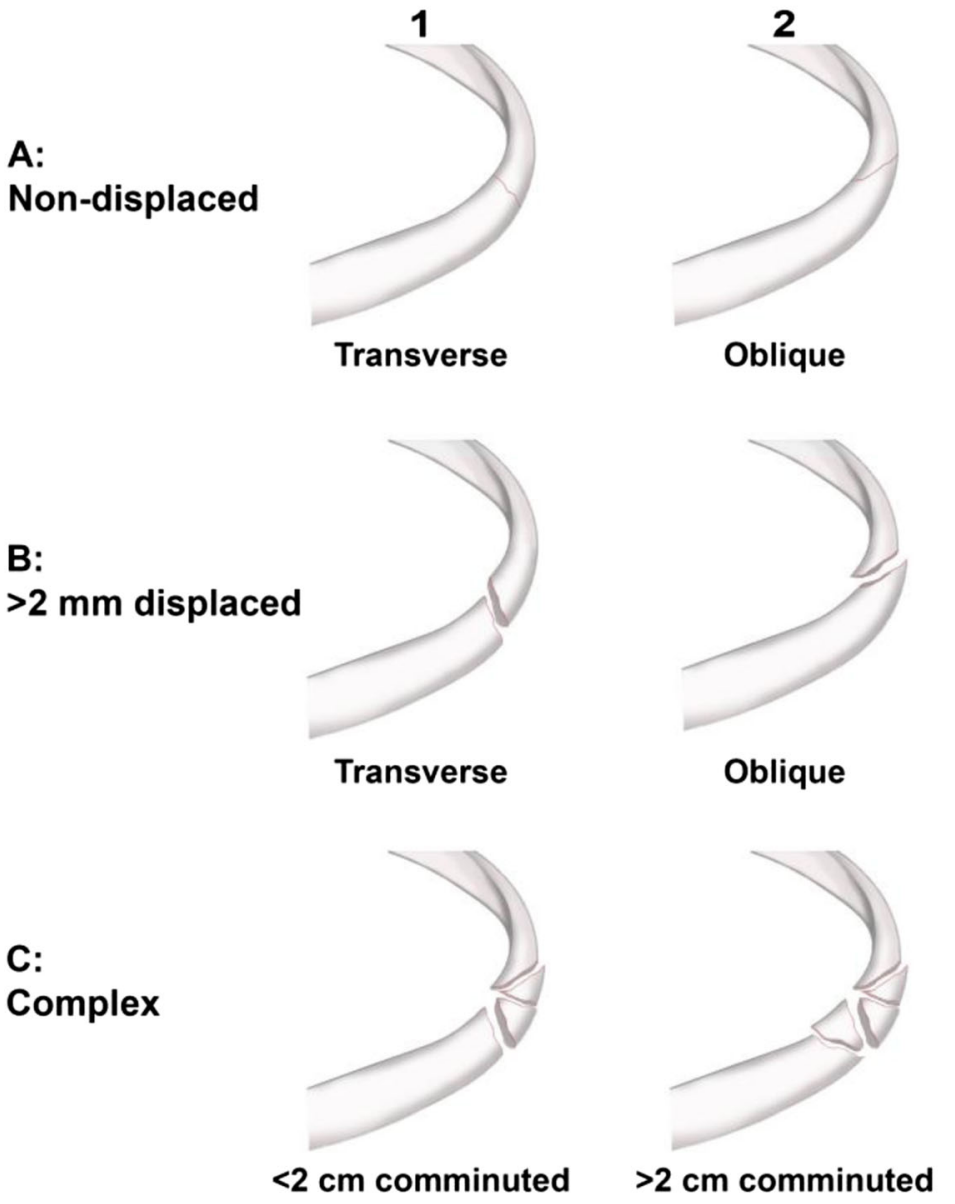

Group

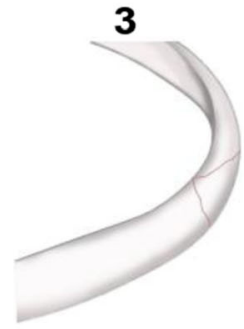

Wedge

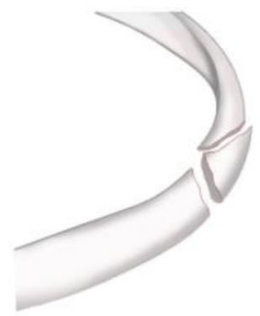

Wedge

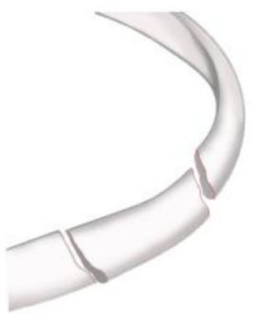

Segmental
Normality of continuous variables was tested with the Shapiro-Wilk test. This showed that all continuous variables deviated from a standard normal distribution. Statistical significance in patients with normal versus diminished BMD was tested; continuous, non-parametric data of two groups were tested using the Mann-Whitney $U$ test. In cases of testing more than two groups, a Kruskal-Wallis one-way analysis of variance test was preformed, with post hoc pairwise comparison with the Mann-Whitney $U$ test performed. Chi-square analysis or Fisher's exact test were used to test categorical data as applicable. A $p$ value lower than 0.05 was considered statistically significant.

\section{Results}

During the study period, a total of 488 patients were registered in the Trauma Department's osteoporosis registry (Fig. 2). Three hundred and fifteen patients were excluded because no DXA scan was performed and 54 patients met other exclusion criteria. A total of 119 patients remained for analysis.
First, analysis was performed comparing patients in the osteopenia group, osteoporosis group, and normal BMD group (Table 1). Since separate groups were small and a diminished BMD might cause decreased bone strength and therefore a higher risk of sustaining fractures, results are presented as a pooled group of patients with diminished BMD (i.e., osteoporosis or osteopenia). Of the 119 patients, 61 (51\%) had a normal BMD and 58 (49\%) had a diminished BMD. Age and gender distribution did not differ between the

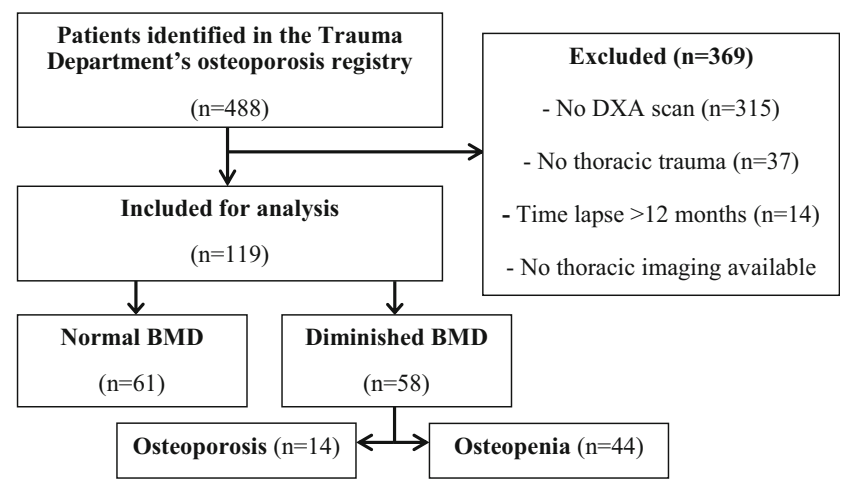

Fig. 2 Flowchart showing inclusion of patients for analysis 
Table 1 Demographics and injury characteristics in patients with normal BMD, osteopenia, and osteoporosis

\begin{tabular}{llllll}
\hline & $\begin{array}{l}\text { Overall } \\
(n=119)\end{array}$ & $\begin{array}{l}\text { Normal BMD } \\
(n=61)\end{array}$ & Osteopenia $(n=44)$ & $\begin{array}{l}\text { Osteoporosis } \\
(n=14)\end{array}$ & $p$ value \\
\hline Rib fracture & $74(62 \%)$ & $31(51 \%)$ & $31(71 \%)$ & $\begin{array}{l}12(86 \%) \\
6(1-8)\end{array}$ & 0.019 \\
Number of ribs fractured & $4(0-7)$ & $1(0-7)$ & $3(0-6)$ & 0.196 \\
\hline
\end{tabular}

Data are shown as $N(\%)$ or median $\left(P_{25}-P_{75}\right)$, statistical significance was tested using chi-squared test or Kruskal-Wallis ANOVA, respectively. Italicized $p$ values are considered statistically significant normal and diminished BMD groups. The median age of all patients was $61\left(P_{25}-P_{75} 54-68\right)$ years and $44(37 \%)$ were female (Table 2). In total, 74 (62\%) patients sustained one or more rib fractures after thoracic trauma. The median number of fractures in the entire cohort was $3\left(P_{25}-P_{75} 0-7\right)$. The suspected mechanism of injury was low-energy trauma in 30 $(25 \%)$ patients.

The diminished BMD group suffered low-energy trauma significantly more often than the normal BMD group (36\% versus $15 \%$, respectively $(p=0.011)$ ). The diminished BMD group also suffered rib fractures more frequently, in $43(74 \%)$ of the patients versus $31(51 \%)$ in the normal BMD group $(p=$ 0.014; Table 2). The median number of rib fractures in patients with at least one fracture did not differ between the groups. Ribs at the cranial segment of the chest wall (ribs 1 to 3 ) were not fractured more often in the diminished BMD group (Table 2). The number of patients with at least one rib fracture of the middle thoracic segment (ribs 4 to 10) was not different between groups $(n=39(91 \%)$ patients of the diminished BMD group and $n=29$ (94\%) in the normal BMD group; $p$ $=1.000$ ).

Intrathoracic injury was seen in 23 patients $(40 \%)$ in the diminished BMD group and in 19 patients $(31 \%)$ in the normal BMD group $(p=0.345)$. Patients with diminished BMD did not have more type A, B, or C fractures (Table 2).

Figure 3 shows the rib fracture type distribution and fracture frequency per rib for both groups. At the end of every bar, the percentage of the displaced and complex fracture types, type B and C correspondingly, combined is given. Patients with diminished BMD did not have type $\mathrm{B}$ and $\mathrm{C}$ fractures ( $n=145$ (65\%) of all fractures) more commonly than patients with normal $\operatorname{BMD}(n=125(64 \%) ; p=0.760)$.

\section{Discussion}

This retrospective study showed that the rate of rib fractures was significantly higher in patients with diminished BMD after blunt thoracic trauma than in patients with a normal BMD.

The higher rib fracture frequency in the diminished BMD group appears to be in line with previous findings. Previous studies reported an almost twofold higher risk of sustaining rib fractures for every standard deviation decrease in BMD and identified diminished BMD as an independent risk factor for rib fractures after substantial thoracic trauma in elderly patients $[24,25]$. Other studies reported that the risk of a future fracture of the ribs, hip, limb, wrist, or spine was at least doubled in elderly men and postmenopausal women with a rib fracture history $[14,15,26,27]$.

The overall HET rate of $74 \%$ in this cohort was high. Lowe et al. and Keller et al. reported a HET rate of around $10 \%$ of trauma admissions in elderly patients aged 65 or older [34, 35]. While these studies were also performed in a level 1 trauma center to which the more severely injured patients are often referred, our inclusion criteria of sustaining thoracic trauma specifically and the relatively younger group of patients (aged 50 years and older) could be an explanation. As the classification of the suspected trauma mechanism is done on-site by a paramedic, the liberal use of defining trauma as high-energy trauma could be another explanation.

In addition, the overall rate of patients with rib fractures in the current cohort (62\%) is high compared with that of Lafferty et al. who reported rib fractures in up to $39 \%$ of patients after blunt thoracic trauma [1]. As the level of the trauma center is not described in Lafferty's study, it remains unknown if a difference in trauma center levels may explain this difference. Also, since we excluded patients who were registered as having sustained thoracic trauma but had no recorded details of any thoracic trauma in their medical files, the remaining study population might have a higher probability of having sustained one or more rib fractures. In this study, over $60 \%$ of the included patients had CT imaging of the thorax after trauma whereas this percentage is unknown in the aforementioned study. In patients who have suffered from HET, there was a low threshold for performing a thoracic CT scan. However, the clinical situation in combination with conventional imaging is leading in this decision. Thoracic CT imaging is superior to chest radiography. Approximately $75 \%$ of all rib fractures which are seen on chest $\mathrm{CT}$ are missed on radiography $[36,37]$. The low sensitivity is aggravated in the trauma setting because chest radiography is performed with the patient in the supine position. Moreover, other potentially severe intrathoracic injuries are much better visualized on a CT scan than on plain radiographs. Accurate diagnosis of the number of rib fractures is relevant because it correlates to mortality [7-9]. As a result, a plain radiograph is inaccurate in identifying high-risk patients. 
Table 2 Demographics and injury characteristics in patients with normal BMD versus diminished BMD

\begin{tabular}{lllll}
\hline & $\begin{array}{l}\text { Overall } \\
(n=119)\end{array}$ & $\begin{array}{l}\text { Normal BMD } \\
(n=61)\end{array}$ & $\begin{array}{l}\text { Diminished BMD } \\
(n=58)\end{array}$ & $p$ value \\
\hline Female gender & $44(37 \%)$ & $20(33 \%)$ & $24(41 \%)$ & 0.349 \\
Age (years) & $61(54-68)$ & $60(54-65)$ & $62(55-73)$ & 0.260 \\
High-energy trauma* & $87(74 \%)$ & $50(85 \%)$ & $37(64 \%)$ & 0.011 \\
Rib fracture & $74(62 \%)$ & $31(51 \%)$ & $43(74 \%)$ & 0.014 \\
Number of ribs fractured & $3(0-7)$ & $1(0-7)$ & $3(0-7)$ & 0.137 \\
Flail chest & $23(27 \%)$ & $10(26 \%)$ & $13(28 \%)$ & 1.000 \\
Proximal rib fracture & $50(68 \%)$ & $22(71 \%)$ & $28(65 \%)$ & 0.625 \\
Intrathoracic injury & $42(35 \%)$ & $19(31 \%)$ & $23(40 \%)$ & 0.345 \\
Pneumothorax & $36(30 \%)$ & $16(26 \%)$ & $20(35 \%)$ & 0.425 \\
Lung contusion & $12(10 \%)$ & $7(12 \%)$ & $5(9 \%)$ & 0.763 \\
Hemothorax & $10(8 \%)$ & $3(5 \%)$ & $7(12 \%)$ & 0.197 \\
Intrathoracic bleeding & $1(1 \%)$ & $0(0 \%)$ & $1(3 \%)$ & 1.000 \\
Arterial dissection & $1(1 \%)$ & $0(0 \%)$ & $1(3 \%)$ & 1.000 \\
Fracture type & & $72(37 \%)$ & $78(35 \%)$ & 0.724 \\
Type A & $150(36 \%)$ & $59(30 \%)$ & $62(28 \%)$ & $83(37 \%)$ \\
Type B & $121(29 \%)$ & $66(34 \%)$ & & \\
Type C & $149(36 \%)$ & & & \\
\hline
\end{tabular}

Data are shown as $N(\%)$ or as median $\left(P_{25}-P_{75}\right)$; italicized $p$ values are considered statistically significant *Data were missing for two patients, both in the diminished BMD group
In a large retrospective review of the National Trauma Data Bank, Flagel et al. suggested that the rate of associated intrathoracic injuries, such as pneumothorax, significantly increased for every additional rib fracture [4]. In this cohort, the diminished BMD group sustained two additional rib fractures after thoracic trauma, but this difference and the frequency of concomitant intrathoracic injuries were not significant between these groups. While the suspected trauma mechanism was significantly more often low-energy trauma in patients with diminished BMD, rib fracture characteristics such as the occurrence of flail chest, concomitant intrathoracic injuries, and rib fracture type did not differ between groups.

While a CT scan is often performed after a HET, a lowered threshold might also be applied to patients aged 50 years and older. As the presence of diminished BMD is associated with both a high rate of rib fractures as well as concomitant intrathoracic injury, thoracic $\mathrm{CT}$ imaging should be considered liberally in these patients. The therapeutic consequence of CT diagnosed versus radiographically diagnosed rib fractures remains debatable and should be studied prospectively [38].

$\mathrm{Kim}$ et al. showed that in patients over 65 years with isolated rib fractures, only $12 \%$ were evaluated for BMD after trauma of which almost half (48\%) had osteoporosis [39]. In our cohort, $35 \%$ of registered patients were evaluated for BMD of which almost half (49\%) had diminished BMD. This highlights the current low awareness of the role of a low BMD and sustaining rib fractures. While rib fractures are considered an osteoporotic fracture by some, it is unknown if rib bones benefit from anti-osteoporotic treatment to prevent subsequent fractures $[15,26]$. Besides, routinely performing a DXA scan after thoracic trauma in patients over 50 years can provide insight into the true prevalence of diminished BMD in this subpopulation.

In an attempt to stratify the injury characteristics, a rib fracture classification has been developed in accordance with the AO/OTA fracture classification (Fig. 1). In this cohort, over $60 \%$ of rib fractures were either displaced (type B), or multifragmentary or segmental (both type C). With the best treatment for rib fractures remaining a subject of debate, a validated classification for rib fractures may aid in diagnosing the severity of rib fractures and would ideally predict outcome. Moreover, it could clearly define those patients who may benefit from operative treatment as flail chest and severely displaced rib fractures are currently indications for operative stabilization $[31,40]$. It must be noted that in around $40 \%$ of patients, no thoracic CT scan was available. This might have affected the accuracy and distribution of the rib fracture types in the current study.

Fractures of the first and second ribs are associated with a higher risk of severe concomitant injuries to e.g. the subclavian structures and thoracic vertebrae [41]. In contrast to middle segment ribs, the individual ribs 1 and 2, and 11 and 12 are neither amenable for surgery nor essential in chest wall stability and respiration $[31,40]$. Surgery therefore adds more to morbidity than benefit [31]. In our cohort, no difference was found in the number of patients who fractured ribs 1 to 3 or 
Normal BMD Diminished BMD

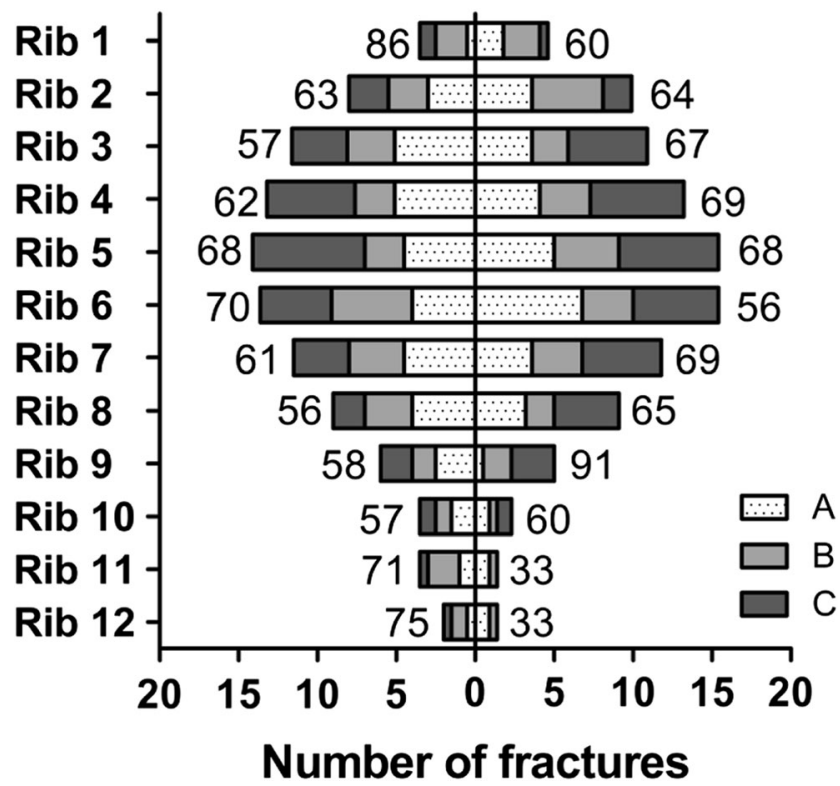

Fig. 3 Distribution of rib fracture subtypes between the two groups. For each rib, the percentage of fractured ribs is shown relative to the total number of rib fractures in the group with normal BMD or diminished $\mathrm{BMD}$, respectively. At the end of every bar, the percentage of type B and $\mathrm{C}$ fractures combined is given for every rib

ribs 4 to 10. Thus, patients with diminished BMD are not more likely to sustain either a complex cranial fracture that is associated with a higher risk of severe complications or a fracture of the middle thoracic segment that could benefit from operative fixation.

The current study has several limitations. The patient group might not be representative of patients aged 50 or older with rib fractures, because it was a single-center study in a level 1 trauma center, and DXA scans were only available for $35 \%$ of patients. The 119 patients selected from the 488 patients registered in the osteoporosis registry might not be able to avoid selection bias and inadequate power. The reason for the low rate of DXA scans remains unclear as this is not elaborated on in the patient's medical file. Possible explanations might include patient's unwillingness for screening or an institutional flaw in complying with the hospital's osteoporosis screening guideline. The sample size was possibly too low to detect small but potentially meaningful differences from a clinical perspective in both fracture and injury characteristics between the normal and diminished BMD groups. In addition, the present study population was too small to analyze outcomes in patients with osteopenia or osteoporosis separately, or to perform multivariable regression. Implementing a standard DXA scan in patients aged 50 or older after rib fractures is recommended to improve understanding of the true prevalence of diminished BMD in these patients. With the retrospective design of this study, outcome measures might have been affected due to missing data and underreporting. For example, the fracture history of the included patients was not available. As this is considered a confounding factor for sustaining fractures in the future, this might have affected the results. A prospective design with a larger sample size is necessary.

Despite these shortcomings, this cohort study is the largest to date that focuses on the role of BMD on rib fracture frequency and characteristics in the middle-aged and elderly patient.

\section{Conclusion}

Patients aged 50 years or older often sustain rib fractures after blunt thoracic trauma. The rate of rib fractures after blunt thoracic trauma was significantly higher in patients with diminished BMD than in patients with a normal BMD. Differences in number and location of rib fractures between groups could not be proven. When assessing patients aged 50 years or older presenting to the hospital after substantial blunt thoracic trauma, the presence of diminished BMD should be taken into account and the presence of rib fractures should be investigated with appropriate diagnostic procedures.

Future prospective studies should determine the impact of diminished BMD on complication and mortality rate after rib fractures, and focus on the therapeutic consequence of performing thoracic $\mathrm{CT}$ imaging at a lower threshold in elderly patients after thoracic trauma.

\section{Compliance with ethical standards}

Conflicts of interest None.

Open Access This article is distributed under the terms of the Creative Commons Attribution-NonCommercial 4.0 International License (http:// creativecommons.org/licenses/by-nc/4.0/), which permits any noncommercial use, distribution, and reproduction in any medium, provided you give appropriate credit to the original author(s) and the source, provide a link to the Creative Commons license, and indicate if changes were made.

\section{References}

1. Lafferty PM, Anavian J, Will RE, Cole PA (2011) Operative treatment of chest wall injuries: indications, technique, and outcomes. J Bone Joint Surg Am 93:97-110

2. Ziegler DW, Agarwal NN (1994) The morbidity and mortality of rib fractures. J Trauma 37:975-979

3. Cameron P, Dziukas L, Hadj A, Clark P, Hooper S (1996) Rib fractures in major trauma. Aust N Z J Surg 66:530-534

4. Flagel BT, Luchette FA, Reed RL, Esposito TJ, Davis KA, Santaniello JM, Gamelli RL (2005) Half-a-dozen ribs: the breakpoint for mortality. Surgery 138:717-723 discussion 723-715

5. Wardhan R (2013) Assessment and management of rib fracture pain in geriatric population: an ode to old age. Curr Opin Anaesthesiol 26:626-631 
6. Barnea Y, Kashtan H, Skornick Y, Werbin N (2002) Isolated rib fractures in elderly patients: mortality and morbidity. Can J Surg 45: 43-46

7. Bergeron E, Lavoie A, Clas D, Moore L, Ratte S, Tetreault S, Lemaire J, Martin M (2003) Elderly trauma patients with rib fractures are at greater risk of death and pneumonia. J Trauma 54:478485

8. Lee RB, Bass SM, Morris JA Jr, MacKenzie EJ (1990) Three or more rib fractures as an indicator for transfer to a level I trauma center: a population-based study. J Trauma 30:689-694

9. Battle CE, Hutchings H, Evans PA (2012) Risk factors that predict mortality in patients with blunt chest wall trauma: a systematic review and meta-analysis. Injury 43:8-17

10. Van Vledder MG, Kwakernaak V, Hagenaars T, Van Lieshout EMM, Verhofstad MHJ (2018) Patterns of injury and outcomes in the elderly patient with rib fractures: a multicenter observational study. Eur J Trauma Emerg Surg 45:575-583. https://doi.org/10. 1007/s00068-018-0969-9

11. Bulger EM, Arneson MA, Mock CN, Jurkovich GJ (2000) Rib fractures in the elderly. J Trauma 48:1040-1046 discussion 10461047

12. Holcomb JB, McMullin NR, Kozar RA, Lygas MH, Moore FA (2003) Morbidity from rib fractures increases after age 45. J Am Coll Surg 196:549-555

13. Chien CY, Chen YH, Han ST, Blaney GN, Huang TS, Chen KF (2017) The number of displaced rib fractures is more predictive for complications in chest trauma patients. Scand J Trauma Resus 25: 19

14. Sajjan SG, Barrett-Connor E, McHorney CA, Miller PD, Sen SS, Siris E (2012) Rib fracture as a predictor of future fractures in young and older postmenopausal women: National Osteoporosis Risk Assessment (NORA). Osteoporos Int 23:821-828

15. Barrett-Connor E, Nielson CM, Orwoll E, Bauer DC, Cauley JA, Osteoporotic Fractures in Men Study G (2010) Epidemiology of rib fractures in older men: Osteoporotic Fractures in Men (MrOS) prospective cohort study. BMJ 340:c1069

16. Jones G, Nguyen T, Sambrook PN, Kelly PJ, Gilbert C, Eisman JA (1994) Symptomatic fracture incidence in elderly men and women: the Dubbo Osteoporosis Epidemiology Study (DOES). Osteoporos Int 4:277-282

17. Stone KL, Seeley DG, Lui LY, Cauley JA, Ensrud K, Browner WS, Nevitt MC, Cummings SR, Osteoporotic Fractures Research G (2003) BMD at multiple sites and risk of fracture of multiple types: long-term results from the Study of Osteoporotic Fractures. J Bone Miner Res 18:1947-1954

18. Melton LJ, Thamer M, Ray NF, Chan JK, Chesnut CH, Einhorn TA, Johnston CC, Raisz LG, Silverman SL, Siris ES (1997) Fractures attributable to osteoporosis: report from the National Osteoporosis Foundation. J Bone Miner Res 12:16-23

19. Hernlund E, Svedbom A, Ivergard M, Compston J, Cooper C, Stenmark J, McCloskey EV, Jonsson B, Kanis JA (2013) Osteoporosis in the European Union: medical management, epidemiology and economic burden. A report prepared in collaboration with the International Osteoporosis Foundation (IOF) and the European Federation of Pharmaceutical Industry Associations (EFPIA). Arch Osteoporos 8:136

20. Marshall D, Johnell O, Wedel H (1996) Meta-analysis of how well measures of bone mineral density predict occurrence of osteoporotic fractures. BMJ 312:1254-1259

21. Riggs BL, Melton LJ 3rd (1995) The worldwide problem of osteoporosis: insights afforded by epidemiology. Bone 17:505S-511S

22. Kanis JA, Borgstrom F, De Laet C, Johansson H, Johnell O, Jonsson B, Oden A, Zethraeus N, Pfleger B, Khaltaev N (2005) Assessment of fracture risk. Osteoporos Int 16:581-589

23. Svedbom A, Hernlund E, Ivergard M, Compston J, Cooper C, Stenmark J, McCloskey EV, Jonsson B, Kanis JA, IOF EURPo
(2013) Osteoporosis in the European Union: a compendium of country-specific reports. Arch Osteoporos 8:137

24. Wuermser LA, Achenbach SJ, Amin S, Khosla S, Melton L Jr (2011) What accounts for rib fractures in older adults? J Osteoporos 2011:457591

25. Mai HT, Tran TS, Ho-Le TP, Pham TT, Center JR, Eisman JA, Nguyen TV (2018) Low-trauma rib fracture in the elderly: risk factors and mortality consequence. Bone 116:295-300

26. Ismail AA, Silman AJ, Reeve J, Kaptoge S, O’Neill TW (2006) Rib fractures predict incident limb fractures: results from the European Prospective Osteoporosis Study. Osteoporos Int 17:41-45

27. van Staa TP, Leufkens HGM, Cooper C (2002) Does a fracture at one site predict later fractures at other sites? - A British cohort study. Osteoporos Int 13:624-629

28. Sirmali M, Turut H, Topcu S, Gulhan E, Yazici U, Kaya S, Tastepe I (2003) A comprehensive analysis of traumatic rib fractures: morbidity, mortality and management. Eur J Cardiothorac Surg 24:133138

29. Edgecombe L, Angus LD (2019) Thoracic trauma. Treasure Island, FL

30. Office of the Surgeon G (2004) U.S. Department of Health and Human Services. Bone health and osteoporosis: a report of the Surgeon General. Rockville, MD

31. Kasotakis G, Hasenboehler EA, Streib EW, Patel N, Patel MB, Alarcon L, Bosarge PL, Love J, Haut ER, Como JJ (2017) Operative fixation of rib fractures after blunt trauma: a practice management guideline from the Eastern Association for the Surgery of Trauma. J Trauma Acute Care Surg 82:618-626

32. Leinicke JA, Elmore L, Freeman BD, Colditz GA (2013) Operative management of rib fractures in the setting of flail chest: a systematic review and meta-analysis. Ann Surg 258:914-921

33. Bemelman M, Baal MV, Raaijmakers C, Lansink K, Leenen L, Long W (2019) An interobserver agreement study with a new classification for rib fractures. Chirurgia (Bucur) 114:352-358

34. Lowe JA, Pearson J, Leslie M, Griffin R (2018) Ten-year incidence of high-energy geriatric trauma at a level 1 trauma center. J Orthop Trauma 32:129-133

35. Keller JM, Sciadini MF, Sinclair E, O'Toole RV (2012) Geriatric trauma: demographics, injuries, and mortality. J Orthop Trauma 26: e161-e165

36. Murphy CE, Raja AS, Baumann BM, Medak AJ, Langdorf MI, Nishijima DK, Hendey GW, Mower WR, Rodriguez RM (2017) Rib fracture diagnosis in the panscan era. Ann Emerg Med 70:904 909

37. Chapman BC, Overbey DM, Tesfalidet F et al (2016) Clinical utility of chest computed tomography in patients with rib fractures CT chest and rib fractures. Arch Trauma Res 5:e37070

38. Singleton JM, Bilello LA, Canham LS, Levenson RB, Lopez GJ, Tadiri SP, Shapiro NI, Rosen CL (2019) Chest computed tomography imaging utility for radiographically occult rib fractures in elderly fall-injured patients. J Trauma Acute Care Surg 86:838-843

39. Kim W, Gong HS, Lee SH, Park JW, Kim K, Baek GH (2017) Low evaluation rate for osteoporosis among patients presenting with a rib fracture. Arch Osteoporos 12:61

40. Pieracci FM, Majercik S, Ali-Osman F, Ang D, Doben A, Edwards JG, French B, Gasparri M, Marasco S, Minshall C, Sarani B, Tisol W, VanBoerum D, White TW (2017) Consensus statement: surgical stabilization of rib fractures rib fracture colloquium clinical practice guidelines. Injury 48:307-321

41. Fokin A, Wycech J, Picard E, Weisz R, Puente I (2018) Is first rib fracture a culprit or a sign of injury severity? It is both. J Orthop Trauma 32:391-396

Publisher's note Springer Nature remains neutral with regard to jurisdictional claims in published maps and institutional affiliations. 